REVISTA DE GESTÃO ESECRETARIADO

MANAGEMENT AND ADMINISTRATIVE

PROFESSIONAL REVIEW

ISSN: 2178-9010
Revista GeSec

São Paulo, SP, Brasil

v. 12, n. 3, p. 37-63

set./dez. 2021

DOI: http://dx.doi.org/10.7769/gesec.v12i3.1218

\title{
Governança corporativa em empresas familiares: impacto dos aspectos socioemocionais em uma empresa da área de saúde
}

\section{Corporate governance in family firms: impact of the socioemotional aspects in a healthcare firm}

\author{
Verônica Andréa Lima Gouveia ${ }^{1}$ \\ Ana Carolina Pimentel Duarte da Fonseca ${ }^{2}$
}

\section{Resumo}

A governança corporativa tem como objetivo mitigar conflitos e alinhar interesses. Na empresa familiar, este desafio é maior devido às inter-relações entre família, propriedade e gestão. Este estudo tem como objetivo compreender como os aspectos socioemocionais impactam os mecanismos de governança corporativa em empresas familiares. Com base na Teoria da Riqueza Socioemocional, realizou-se uma pesquisa descritiva, com abordagem qualitativa, através de entrevistas em profundidade em uma empresa familiar da área de saúde, voltada para o setor de pediatria, e presente no mercado há 59 anos. Os resultados evidenciaram que os mecanismos de governança corporativa sofreram impacto dos aspectos socioemocionais presentes na empresa familiar pesquisada, o que faz com que se diferenciem dos mecanismos de governança usualmente descritos na literatura. Este estudo contribuiu para a literatura sobre governança corporativa ao constatar sua baixa efetividade junto às empresas familiares, tendo em vista suas peculiaridades. Neste sentido, a literatura sobre governança corporativa deveria incorporar os aspectos socioemocionais ao seu arcabouço conceitual para que esta deixasse de ser inócua às empresas familiares, passando a contribuir efetivamente com a gestão e com a continuidade deste tipo de organização tão relevante, especialmente no Brasil.

Palavras-Chaves: Empresas Familiares. Aspectos Socioemocionais. Mecanismos de Governança. Teoria da Riqueza Socioemocional.

\begin{abstract}
Corporate governance aims to mitigate conflicts and align interests. In the family firms, this challenge is greater due to the interrelationships between family, property and management. This study aims to understand how socioemotional aspects impact corporate governance mechanisms in family firms. Based on the Socioemotional Wealth Theory, a descriptive research was carried out, with a qualitative approach, through in-depth interviews in a family health company, focused on the pediatric sector, and present in the market for 59 years. The

\footnotetext{
${ }^{1}$ Doutoranda no Programa de Pós-graduação em Ciências Contábeis da Universidade Federal do Rio de Janeiro (UFRJ).

${ }^{2}$ Doutora em Administração, Docente no Programa de Pós-graduação em Ciências Contábeis da UFRJ.
} 
results showed that the corporate governance mechanisms were impacted by the socioemotional aspects present in the researched family firm, which makes them different from the governance mechanisms usually described in the literature. This study contributed to the literature on corporate governance by verifying its low effectiveness with family firms, in view of their peculiarities. In this sense, the literature on corporate governance should incorporate socioemotional aspects into its conceptual framework so that it ceases to be innocuous to family firms, starting to contribute effectively to the management and continuity of this type of organization, which is so relevant, especially in Brazil.

Keywords: Family Firms. Socioemotional Aspects. Governance Mechanisms. Socioemotional Wealth Theory.

\section{Introdução}

As empresas familiares, com frequência, adotam mecanismos formais de governança para satisfazer as necessidades externas (Teunissen, 2014 e Briano-Turrenta \& PolettiHughesb, 2017), porém utilizam outros mecanismos que atendem às suas peculiaridades (Nordqvist, Sharma \& Chirico, 2014). Neste sentido, a lógica das empresas familiares pode ser conflitante com a lógica da governança corporativa, uma vez que os objetivos das empresas familiares podem ser singulares, englobando aspectos não exclusivamente financeiros (Berrone, Cruz \& Gomez-Mejia, 2012).

A governança corporativa tem como objetivo mitigar conflitos e alinhar interesses. $\mathrm{Na}$ empresa familiar, este desafio é maior devido às inter-relações entre família, propriedade e gestão. É possível verificar uma abordagem preponderante da governança corporativa nas empresas familiares para atender stakeholders externos, ou seja, uma visão de dentro para fora da organização com o intuito de propagar sua reputação, conforme analisado empiricamente pelos estudos de Liu, Valenti e Chen (2016), Minichilli, Brodi e Calabrò (2016), BrianoTurrenta e Poletti-Hughesb (2017) e Ciftci et al. (2019).

As aspirações de empresas influenciadas ou controladas por famílias complicam o desafio da governança. A Governança Corporativa é um conjunto de mecanismos usados para garantir que as ações das partes interessadas (stakeholders) sejam consistentes com os objetivos da coalizão dominante (Steir, Chrisman \& Chua, 2015). Portanto, é necessário entender o contexto das empresas familiares e a importância dos relacionamentos e dos vínculos que permeiam a família empresária, organizando as relações de afeto, poder e dinheiro por meio da governança corporativa (Steinberg e Blumenthal, 2011).

A Teoria da Riqueza Socioemocional aborda aspectos socioemocionais inerentes às empresas familiares incluindo o controle e a influência da família na gestão, a identificação da família com a empresa, os laços sociais, o apego emocional, a necessidade de renovação de 
laços familiares através da sucessão. Refere-se aos aspectos não financeiros ou "necessidades afetivas" de proprietários da família e sugere que as empresas familiares são tipicamente motivadas e comprometidas com a preservação de suas práticas. Esta teoria diferencia a empresa familiar como uma entidade única, o que ajuda a explicar por que as empresas familiares se comportam de maneira distinta das demais empresas (Berrone, Cruz \& GomezMejia, 2012).

Assim, é necessário entender quais mecanismos de governança são úteis para as empresas familiares. O desafio é encontrar mecanismos de governança que ajudem a maximizar as vantagens e superar as desvantagens resultantes do envolvimento da família nos negócios (Nordqvist, Sharma e Chirico, 2014).

Estudos anteriores como os de Steir, Crisman e Chua (2015) e Ciftci et al. (2019) abordaram os desafios de governança e a necessidade de mecanismos de controle para o melhor desempenho nas empresas familiares. Outros estudos (Berrone, Cruz \& Gomez-Mejia, 2012; Perry, Ring \& Brober, 2015; Golden \& Kohlbeck, 2016 e Lee, Makri \& Scandura, 2019, Liu, Valenti e Chen (2016), Minichilli, Brodi e Calabrò (2016), diante dos aspectos socioemocionais presentes nas empresas familiares, verificaram a importância de se criar estruturas de governança nestas empresas que atendam às suas particularidades. Porém, existe uma lacuna teórica na compreensão de como funciona a governança nas empresas familiares, sendo necessário considerar que podem existir outros mecanismos para minimizar conflitos e gerenciar diferentes pontos de vista para o alcance dos objetivos organizacionais, não necessariamente os descritos na literatura. Além disso, grande parte do que sabemos sobre a governança corporativa em empresas familiares está baseada em estudos internacionais. É necessário fomentar e avançar a pesquisa acadêmica sobre a Governança de Empresas Familiares no Brasil (Bressan et al., 2019).

Para Chrisman et al. (2018), a governança é um fator determinante da distinção e heterogeneidade das empresas familiares. Os autores sugerem que, embora os mecanismos formais de governança nas empresas familiares tenham características singulares, os mecanismos informais de governança podem ser igualmente importantes e podem influenciar o comportamento da empresa. Mecanismos formais são codificados por leis e regulamentos, enquanto os mecanismos informais, embora não codificados, são representados por pressões por conformidade, acomodação ou adaptação aos valores da sociedade na qual a empresa está inserida.

Desta forma, compreender como as questões socioemocionais presentes nessas empresas se refletem na sua governança permitiria o reconhecimento de práticas de gestão que, 
embora não citadas na literatura sobre governança, fazem sentido e são utilizadas como mecanismos de governança nas empresas familiares. Neste contexto, o problema que se apresenta para esta pesquisa é: Como os aspectos socioemocionais presentes nas empresas familiares impactam os mecanismos de governança corporativa?

Assim o objetivo do estudo é compreender como os aspectos socioemocionais impactam os mecanismos de governança corporativa em empresas familiares. Para o cumprimento deste objetivo realizou-se uma pesquisa descritiva, com abordagem qualitativa, em uma empresa familiar da área de saúde, voltada para o setor de pediatria, e presente no mercado há 59 anos.

Este artigo contribui para a literatura sobre governança corporativa ao verificar sua aplicabilidade e efetividade em empresas familiares, tendo em vista os aspectos socioemocionais que as tornam peculiares. A relevância das empresas familiares, especialmente no Brasil, reforça a importância deste tipo de verificação.

\section{Referencial Teórico}

\subsection{Empresas Familiares e Teoria da Riqueza Socioemocional}

Chua, Chrisman e Sharma (1999) definem as empresas familiares como aquelas que têm seu alicerce na visão da família controladora com foco em manter a empresa através das gerações. De acordo com Frank et al. (2016), existe um conjunto de capacidades e recursos exclusivos de uma empresa familiar, denominado familiness, que é derivado do envolvimento da família proprietária com os negócios. Assim,familiness é o conjunto de premissas de decisão que expressam a influência da família nos negócios.

Carrieri, Perdigão e Aguiar (2014) ressaltam que as discussões que envolvem organizações familiares exigem um aprofundamento no tema da construção das significações culturais e identitárias, das influências que o contexto e o meio cultural exercem sobre essa construção, da mistura entre os espaços da família e do negócio. Na gestão das empresas familiares, portanto, é preciso levar em conta os fatores históricos, sociais, culturais e identitários que diferenciam os sujeitos e, na prática cotidiana, ampliam a gestão.

Para Gersick et al., (2017), as empresas familiares extraem uma força especial da história, da identidade e da linguagem comuns às famílias. A história da família fortalece os laços entre seus membros. Os propósitos e valores da família impulsionam as novas gerações para a continuidade do legado familiar. 
Com base na literatura de negócios da família e nas disciplinas de ciências sociais, Berrone, Cruz e Gomez-Mejia, (2012) propuseram cinco dimensões da riqueza socioemocional descritas conforme a figura 1 :

\begin{tabular}{|c|c|}
\hline \multicolumn{2}{|r|}{ Riqueza socioemocional } \\
\hline Dimens ões & Caracteríticas \\
\hline $\begin{array}{l}\text { Controle e influência da } \\
\text { família }\end{array}$ & $\begin{array}{l}\text { A primeira dimensão refere-se ao controle e influência dos membros da família. Uma } \\
\text { característica-chave que distingue as empresas familiares é que os membros da família } \\
\text { exercem controle sobre as decisões estratégicas. }\end{array}$ \\
\hline $\begin{array}{l}\text { Identificação de membros } \\
\text { da família com a empresa }\end{array}$ & $\begin{array}{l}\text { A segunda dimensão aborda a identificação próxima da família com a empresa. O } \\
\text { entrelaçamento entre familia e empresa dá origem a uma identidade inerentemente única } \\
\text { dentro das empresas familiares. }\end{array}$ \\
\hline Laços sociais obrigatórios & $\begin{array}{l}\text { A terceira dimensão refere-se às relações sociais das empresas familiares. As empresas } \\
\text { familiares estão profundamente enraizadas em suas comunidades e frequentemente } \\
\text { patrocinam associações e atividades que são valorizadas na comunidade. }\end{array}$ \\
\hline $\begin{array}{l}\text { Apego emocional dos } \\
\text { membros da família }\end{array}$ & $\begin{array}{l}\text { A quarta dimensão trata do conteúdo afetivo da riqueza socioemocional e refere-se ao papel } \\
\text { das emoções no contexto das empresas familiares. Essas emoções resultam de situações } \\
\text { cotidianas e não são estáticas, à medida que surgem e evoluem através de eventos mais ou } \\
\text { menos críticos em cada sistema de negócios da família (sucessão, divórcio, doença, perda de } \\
\text { família ou negócios, crise econômica). }\end{array}$ \\
\hline \begin{tabular}{lcr|} 
Renovação & de & laços \\
familiares & através & $\mathrm{da}$ \\
sucessão & & \\
\end{tabular} & $\begin{array}{l}\text { A quinta e última dimensão refere-se à intenção de entregar o negócio às gerações futuras. A } \\
\text { sustentabilidade transgeracional como um dos aspectos centrais da riqueza socioemocional. }\end{array}$ \\
\hline
\end{tabular}

Figura 1. Cinco dimensões da riqueza socioemocional

Fonte: Adaptado de Berrone, Cruz e Mejia (2012).

De acordo com Berrone, Cruz e Gomez-Mejia, (2012), as dimensões da riqueza socioemocional representam, portanto, os aspectos não financeiros ou "necessidades afetivas" que estão intrinsecamente ligados aos laços de parentesco, de modo que sua presença afeta o desempenho da empresa. Todos estes aspectos peculiares das empresas familiares demonstram como as empresas familiares se comportam de forma distinta das demais empresas.

Estudos empíricos como os de Chen et al. (2014), Strike et al. (2015), Fang et al. (2016), Kabbach de Castro, Aguilera e Crespí-Cladera (2017) e Vandekerkhof et al. (2018) reforçam a importância da preservação da riqueza socioemocional para as empresas familiares e apontam que questões como o controle familiar e reputação são relevantes para as empresas familiares.

Steinberg e Blumenthal (2011) ressaltam que é necessário entender o contexto das empresas familiares e a importância dos relacionamentos e dos vínculos que permeiam a família empresária. Para Jiang et al. (2018) a riqueza socioemocional provoca decisões e comportamentos únicos em uma empresa familiar e captura a essência do que diferencia este tipo de empresa em relação a outras formas organizacionais. 
Os estudos de Zellweger et al., (2011) abordam as intenções das famílias para o controle transgeracional. Uma das principais áreas de influência da família nos negócios inclui a orientação transgeracional (Frank et al., 2016). Para Le Breton-Miller et al. (2004) a sucessão é um dos maiores desafios enfrentados pelas empresas familiares, sendo a preocupação mais importante de seus líderes. A renovação dos laços familiares através da sucessão é um dos aspectos centrais da riqueza socioemocional (Berrone, Cruz \& Gomez-Mejia, 2012).

\subsection{Governança em Empresas Familiares}

Para o Instituto Brasileiro de Governança Corporativa - IBGC (2016), a governança corporativa em empresas de controle familiar se estabelece, não apenas no âmbito da separação entre propriedade e gestão (como no caso das empresas não familiares), mas, também, no âmbito das relações entre família, propriedade e gestão.

Conforme Gersick et al. (2017), o modelo conceitual dos três círculos surgiu através do trabalho de Tagiuri e Davis no início dos anos 80, onde afirmavam que as empresas familiares são compostas por dois círculos superpostos: a família e a gestão. Posteriormente, o modelo foi aprimorado, incluindo o círculo da propriedade para distinguir proprietários familiares e não familiares que fazem parte ou não da gestão. Esse modelo explica o relacionamento existente nos sistemas das empresas familiares, com seus conflitos e interações, conforme figura 2:

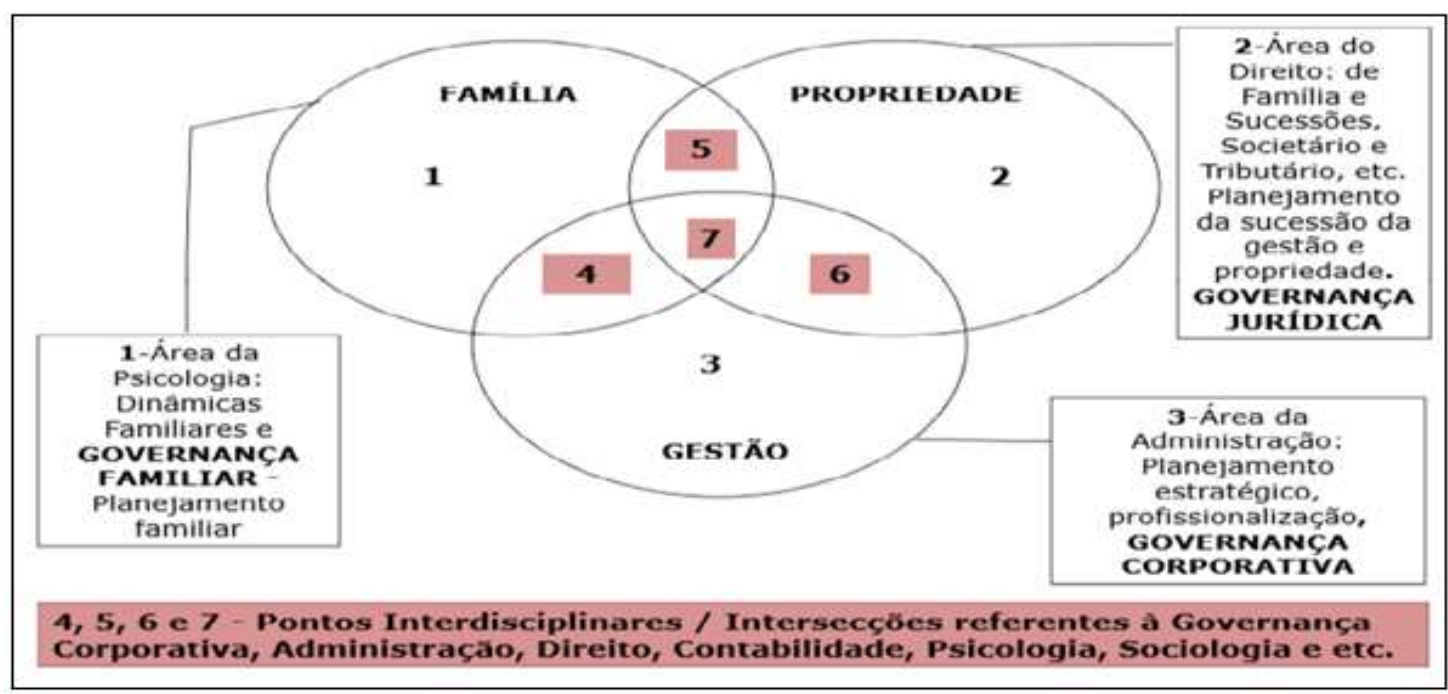

Figura 2. Modelo dos três círculos da empresa familiar

Fonte: Capobianco (2011, p. 4); Prado (2012, p. 49).

A governança corporativa, fundamentalmente relativa ao círculo da gestão, atua no âmbito dos negócios para buscar garantir a sustentabilidade e a proteção de ativos, a imagem 
da empresa, sua reputação e sua relação com as partes interessadas (por exemplo: governo, sócios, clientes e empregados). A governança familiar atua no âmbito da família, abordando a relação desta com seus membros, com a propriedade, com a empresa e com partes interessadas (IBGC, 2016). Por fim, de acordo com Prado et al. (2012), a governança jurídico-sucessória é compreendida como a adequada estrutura de planejamento sucessório nos âmbitos dos Direitos Societário, da Família e das Sucessões. Conforme os pontos 4, 7 e 6 evidenciados na figura 2, a governança corporativa contempla também aspectos da governança familiar e jurídicosucessória.

Os principais fóruns para atender às necessidades de governança são: o Conselho de Administração na Governança Corporativa, o Conselho de Família na Governança Familiar e o Conselho de Acionistas na Governança Jurídico-Sucessória (Bernhoeft, 2014 e Davis, 2019). Conforme Prado et al. (2012) é importante ter presente que a governança corporativa, familiar e jurídico-sucessória, ideal, não é fácil de ser alcançada em sua plenitude. E em vários casos nem é necessária, ou possível, bastando que a empresa ou a família tenham algum tipo de governança efetiva para que a sucessão, tanto da gestão quanto da propriedade do controle de uma empresa familiar, se dê de forma a atender os interesses e a preservação da empresa e da família.

De acordo com Nordqvist, Sharma e Chirico (2014), nas empresas onde o proprietário é o gestor, elas não usam ou não precisam de mecanismos formalizados de governança para evitar a carga de tempo e recursos do proprietário-gestor na sua implementação. O proprietário tem autoridade, legitimidade e incentivos para administrar a empresa. No entanto, existe uma oportunidade para o proprietário-gestor semear as sementes de governança usando mecanismos que iniciem boas práticas.

Para Steier, Chrisman e Chua (2015) a governança é amplamente reconhecida como um fator determinante no sucesso e fracasso de toda a atividade organizadora. O envolvimento da família introduz uma dimensão única na governança. Embora os modelos corporativos tradicionais de governança reconheçam a diversidade das partes interessadas, eles não explicam adequadamente as várias permutações de partes interessadas e interesses que se manifestam em empresas influenciadas por famílias.

Teunissen (2014) faz uma crítica às questões de governança e argumenta que empresas familiares existem em todas as formas legais disponíveis e muitas delas não são listadas em bolsa. No entanto, a maioria dos países desenvolve códigos de governança corporativa que se concentram apenas em empresas listadas em bolsa, ou seja, uma governança para atender aos investidores externos e formalidades do mercado. 
Para Nordqvist, Sharma e Chirico (2014), o envolvimento da família na propriedade e gestão dos negócios varia significativamente dentro das empresas familiares. Embora a literatura reconheça a diversidade nas empresas familiares, ainda não está claro quais mecanismos de governança são mais apropriados para alcançar as metas de desempenho priorizadas de diferentes tipos de empresas familiares. É necessário entender quais mecanismos de governança são úteis para diferentes tipos de empresas familiares.

Chrisman et al. (2018) afirmam que os mecanismos de governança consistem em regras, práticas e processos formais e informais que emanam de dentro e de fora de uma empresa, para direcionar e controlar o comportamento da empresa de forma a equilibrar e alinhar os interesses de seus stakeholders, incluindo proprietários, gerentes, clientes, fornecedores, governo e a comunidade.

Para Birnberg e Snodgrass (1988), a cultura afeta o controle. Os estudos consideraram o argumento de Ouchi (1979) sobre a noção de "clã", ou controle de clã, onde a cultura sob certas circunstâncias pode fornecer um elemento de sinergia para o sistema de controle e facilitar sua operação. Uma cultura consiste em uma variedade de elementos, incluindo valores, crenças e padrões de comportamento. Portanto, membros de grupos de cultura diferentes podem reagir de maneira diferente ao mesmo mecanismo de controle ou exigir mecanismos de controle diferentes para obter o mesmo comportamento. Assim, não há razão para acreditar que um único sistema de controle gerencial seja apropriado para todos os grupos culturais.

De acordo com Anthony e Govindarajan (2006), um sistema formal de controle é constituído por planos estratégicos, orçamentos e relatórios. Por outro lado, a ética do trabalho, o estilo gerencial e a cultura são exemplos de processos informais numa organização. A ética do trabalho consiste no comportamento desejável na forma de lealdade dos funcionários à organização, diligência, espírito e orgulho de ter um bom desempenho. $O$ estilo de gerenciamento impacta no controle gerencial, normalmente a atitude dos funcionários originase da atitude do executivo-chefe. A cultura da organização abrange convicções, atitudes, normas, relacionamentos e presunções em toda a organização. A cultura é fortemente influenciada pela personalidade e pelas políticas do executivo-chefe. As tentativas para alterar práticas encontram resistência e, quanto maior e mais madura for a organização, maior é a resistência.

\section{Metodologia}

\subsection{Procedimentos de Pesquisa}


Esta pesquisa caracteriza-se como descritiva e possui uma abordagem qualitativa com base em entrevistas em profundidade com membros da família e gestores da empresa.

O estudo é descritivo, pois procura expor os aspectos socioemocionais presentes na empresa familiar e que podem contribuir para a análise da governança corporativa neste tipo de empresa. Optou-se ainda pela abordagem qualitativa por permitir, segundo Gerhardt e Silveira (2009), o aprofundamento da compreensão de uma organização e explicação da dinâmica das relações sociais.

Como instrumento de coleta de dados optou-se pela entrevista episódica. Segundo Bauer e Gaskell (2019), a entrevista episódica é uma combinação do enfoque de tipo narrativo e argumentativo, ela pode percorrer várias sequências de narração e subsequente questionamento. Enquanto as entrevistas narrativas revelam as diversas perspectivas dos entrevistados ao contarem histórias sobre acontecimentos e sobre si mesmos, a entrevista episódica se baseia em um guia de entrevista com o fim de orientar o entrevistador para os campos específicos a respeito dos quais se buscam narrativas e respostas. O episódio é um acontecimento ou situação específica que o entrevistado recorda. Para a entrevista, utilizou-se um roteiro semiestruturado com base nos estudos de Berrone, Cruz, Gomez-Mejia, (2012) sobre os aspectos socioemocionais inerentes às empresas familiares.

A técnica utilizada para análise das transcrições das entrevistas realizadas nesta pesquisa foi a análise de conteúdo. Este tipo de análise funciona por desmembramento do texto em categorias. Entre as diferentes possibilidades de categorização encontra-se a análise temática (Fonseca, 2005). Dessa forma, os dados das transcrições das entrevistas foram agrupados nas seguintes categorias simbólicas ou temáticas: os aspectos socioemocionais, tais como, o controle e a influência da família na gestão, a identificação da família com a empresa, os laços sociais, o apego emocional, a sucessão dos membros da família nos negócios e, por fim, os mecanismos de governança existentes para a gestão na empresa familiar pesquisada.

A técnica de análise de conteúdo permite capturar as dimensões da riqueza socioemocional. Ela pode ser usada por estudiosos da empresa familiar para permitir o estudo de percepções e crenças que são geralmente difíceis de obter por outros meios (Berrone, Cruz e Gomez-Mejia, 2012).

\subsection{Caracterização da Empresa Analisada e Perfil dos Participantes da Pesquisa}

A pesquisa refere-se a uma empresa familiar pertencente à área de saúde. O grupo é composto por seis unidades de negócios voltadas para a pediatria. Fundada em 1961 por seis 
médicos de diferentes famílias, hoje pertence somente ao filho de um dos fundadores, que foi comprando a parte de todos os sócios. Está, portanto, na segunda geração na gestão dos negócios. A empresa é uma Sociedade Limitada, considerada de médio porte em termos de faturamento anual. Atua na cidade do Rio de Janeiro há 59 anos, sendo responsável por cerca de 1.500 funcionários, além de contar com a maior emergência pediátrica do estado realizando, em média, 6.000 atendimentos por mês.

A escolha da empresa foi motivada pela presença familiar nos negócios, pela longevidade que possui no mercado, 59 anos de história, e pelo acesso aos participantes da pesquisa. $\mathrm{O}$ acesso à empresa foi possível devido ao contato de uma das autoras deste artigo com o empresário e seus herdeiros em um curso de aperfeiçoamento em Gestão de Empresas Familiares, realizado em uma universidade do Rio de Janeiro, ao longo do ano de 2019. O curso teve por objetivo proporcionar ferramentas de gestão e instrumentos de governança no contexto da empresa familiar.

Os participantes foram escolhidos por serem considerados pessoas-chave tanto pela direção da empresa como pelas autoras, e poderem contribuir com suas experiências vividas como gestores, proprietários ou herdeiros da família. Assim, no final de 2019 e início de 2020, foram realizadas entrevistas presenciais na sede administrativa do grupo hospitalar, orientadas por um roteiro prévio, gravadas e respondidas pelo diretor-presidente, seus 2 herdeiros e 11 gestores da empresa pesquisada. Os entrevistados pertencem a 3 unidades de negócios (hospital, homecare e centro pediátrico), responsáveis por cerca de $95 \%$ do faturamento do grupo. As entrevistas foram transcritas e analisadas para o alcance do objetivo da pesquisa. Os membros da família foram identificados e os gestores foram numerados aleatoriamente para preservar a confidencialidade das respostas.

A figura 3 apresenta o perfil dos entrevistados da pesquisa na empresa familiar em estudo: 


\begin{tabular}{|c|c|c|c|c|c|c|c|}
\hline Posição Atual & $\begin{array}{c}\text { Unidade de } \\
\text { Negócio }\end{array}$ & $\begin{array}{c}\text { Tempo na } \\
\text { empresa } \\
\text { (anos) }\end{array}$ & $\begin{array}{c}\text { Membro da } \\
\text { Família }\end{array}$ & Gênero & $\begin{array}{c}\text { Idade } \\
\text { (anos) }\end{array}$ & $\begin{array}{c}\text { Formação } \\
\text { Acadêmica }\end{array}$ & $\begin{array}{c}\text { Tempo de } \\
\text { entrevista }\end{array}$ \\
\hline Diretor-Presidente & Grupo & 38 & Sim & Masculino & 58 & Pós-doutorado & $1 \mathrm{~h} 17 \mathrm{~min}$ \\
\hline Herdeira & Grupo & - & Sim & Feminino & 28 & Graduação & $47 \mathrm{~min}$ \\
\hline Herdeiro & Grupo & - & Sim & Masculino & 22 & $\begin{array}{c}\text { Graduação em } \\
\text { Andamento }\end{array}$ & $47 \mathrm{~min}$ \\
\hline Superintendente & Grupo & 15 & Sim & Feminino & 46 & Pós-graduação & $1 \mathrm{~h} 20 \mathrm{~min}$ \\
\hline Diretora Médica & $\begin{array}{c}\text { Centro } \\
\text { Pediátrico }\end{array}$ & 29 & Não & Feminino & 54 & Pós-graduação & $1 \mathrm{~h} 19 \mathrm{~min}$ \\
\hline Diretora Médica & Homecare & 22 & Não & Feminino & 48 & Pós-graduação & $55 \mathrm{~min}$ \\
\hline Gerente Médica & $\begin{array}{c}\text { Centro } \\
\text { Pediátrico }\end{array}$ & 20 & Não & Feminino & 47 & Pós-graduação & $56 \mathrm{~min}$ \\
\hline Gerente de Qualidade & Hospital & 12 & Não & Feminino & 35 & Pós-graduação & $57 \mathrm{~min}$ \\
\hline Diretora Médica & Hospital & 10 & Não & Feminino & 36 & Graduação & $1 \mathrm{~h} 19 \mathrm{~min}$ \\
\hline Gerente Administrativa & Hospital & 9 & Não & Feminino & 39 & Pós-graduação & $1 \mathrm{~h} 28 \mathrm{~min}$ \\
\hline Gerente Financeira & Hospital & 3 & Não & Feminino & 38 & Graduação & $1 \mathrm{~h} 28 \mathrm{~min}$ \\
\hline $\begin{array}{c}\text { Coordenadora Médica de } \\
\text { Emergência }\end{array}$ & Hospital & 3 & Não & Feminino & 36 & Pós-graduação & $25 \mathrm{~min}$ \\
\hline $\begin{array}{c}\text { Coordenadora Médica do } \\
\text { Transporte }\end{array}$ & Hospital & 3 & Não & Feminino & 46 & Graduação & $51 \mathrm{~min}$ \\
\hline Diretora Administrativa & Homecare & 1 & Não & Feminino & 56 & Pós-graduação & $1 \mathrm{~h} 18 \mathrm{~min}$ \\
\hline
\end{tabular}

Figura 3. Perfil dos entrevistados

Fonte: Elaborado pelas autoras

Foram elaborados roteiros diferenciados para o diretor-presidente e para os demais entrevistados. Para o diretor-presidente foi proposta uma narrativa sobre a gestão atual da empresa e os planos para o futuro intercalando perguntas abertas com propostas de narrativas. Para os herdeiros e gestores, o roteiro de entrevistas contemplou perguntas abertas e propostas de narrativas sobre a compreensão dos aspectos socioemocionais na gestão e nas decisões da empresa.

\section{Análise e Discussão dos Resultados}

As principais categorias temáticas identificadas com base na análise dos dados e na revisão de literatura foram (1) a influência da riqueza socioemocional na gestão e (2) os mecanismos de governança corporativa adotados pela empresa familiar.

\subsection{Influência da Riqueza Socioemocional na Gestão}

A influência da riqueza socioemocional foi dividida em subcategorias, propostas por Berrone, Cruz e Gomez-Mejia, (2012) de acordo com a teoria socioemocional.

\section{Controle e influência da família}


O diretor-presidente é o principal gestor da empresa, possuindo total influência nas decisões e estratégias da empresa conforme opinião dos gestores abaixo:

$\mathrm{Eu}$ acho que ele influencia muito, na realidade ele é muito centralizador na gestão. Ele faz questão de participar de tudo, ele deixa bem claro isso. É claro que a gente tem alguma autonomia até certo ponto, mas na hora de alguma decisão, alguma coisa que é importante, algum contrato, ele está sempre participando. Ele faz muita questão, inclusive se a gente não chama, ele reclama e diz: "eu quero participar, eu quero fazer". E na realidade, todas as decisões de coisas de alta gestão, é ele que toma. Ele participa de tudo. [Gestor 4]

Então assim, o doutor é a cabeça, ele é o estrategista e eu tenho o maior respeito porque ele montou uma estrutura muito boa. [Gestor 1]

Em linha com os estudos de Berrone, Cruz e Gomez-Mejia, (2012), uma característicachave que distingue as empresas familiares é que os membros da família exercem controle sobre as decisões estratégicas. É o caso da empresa pesquisada em que o diretor-presidente exerce o controle sobre as decisões estratégicas.

Com relação à influência da família, os herdeiros ainda não fazem parte da gestão. A superintendente considera que atualmente tem uma influência na gestão, mas que esta é controlada pelo diretor-presidente, proprietário de 100\% das cotas.

Questões familiares, de amizade ou gratidão impactam na tomada de decisão do diretorpresidente. Os funcionários consideram a empresa uma grande família e isso tem um peso nas decisões conforme relatado:

Minha impressão é que ele pondera muito quando um funcionário não está indo bem, no sentido de mandar o funcionário embora, porque existe um laço aí de amizade, ele é muito grato a muitos funcionários. A empresa já passou por fases muito ruins, é complicado... algumas pessoas abraçaram muito essa causa e ele se sente muito grato, muito agradecido e isso influencia nas decisões dele sim. [Gestor 2]

Para Carrieri, Perdigão e Aguiar (2014) as discussões que envolvem organizações familiares exigem um aprofundamento no tema da construção das significações culturais e identitárias, das influências que o contexto e o meio cultural exercem sobre essa construção, da mistura entre os espaços da família e do negócio.

\section{Identificação de membros da família com a empresa}

Os herdeiros sentem que a empresa interfere muito nas suas vidas e que fazem parte do negócio. Embora não façam parte da gestão, o fato de terem feito um curso de gestão de empresas familiares, para terem uma melhor visão dos negócios, sugere que se identificam com 
a empresa, na medida em que consideram a possibilidade de trabalharem na empresa. Por outro lado, relataram diferentes níveis de identificação:

Eu me identifico, tenho bastante carinho. Eu acho que é você dar uma continuidade a tudo que meu avô começou, meu pai continuou, eu sou da linhagem, tá continuando comigo... passando por várias eras. [Herdeira]

Eu não sei se eu me identifico muito, mas eu me sinto parte da empresa porque desde pequeno a gente conhece tanta gente que trabalha lá... [Herdeiro]

O diretor-presidente admite ter uma identificação total com o negócio. O trecho abaixo demonstra o significado da empresa para ele e a ênfase nos objetivos não financeiros do negócio:

É um filho pra mim! Eu trato o hospital como se fosse um terceiro filho, com carinho... Eu só sei fazer isso! Vou ganhar pouco, dane-se, não é isso... eu não tô aqui para ganhar dinheiro, tô aqui para ser feliz, para me realizar, não é a grana que me realiza.

Na visão dos gestores, há total identificação do proprietário com a empresa e o negócio faz parte da vida dele conforme depoimentos a seguir:

Isso aqui é a vida dele, $100 \%$ ele vive o hospital, é uma rotina louca diária, ele manda e-mail às 4 da manhã, super organizado e eu acho que isso é a vida dele! [Gestor 6]

Eu penso que isso aqui pra ele é um filho. Então assim, ele cuida, ele tem amor, ele tem carinho, ele chora por isso daqui... [Gestor 7]

Conforme os relatos dos mesmos gestores contatou-se também que os clientes (pacientes, pais, familiares das crianças internadas) associam o nome do proprietário aos serviços oferecidos pela empresa. Além disso, há uma identificação de prestadores de serviços e fornecedores com o proprietário do negócio:

Acho que associam o nome do doutor ao hospital até porque a gente se destaca na pediatria. Tanto na parte dos bancos, quanto nos convênios médicos, o nome dele é bem conhecido. O nome é bem forte. Não tem quem não conheça ele. [Gestor 6]

Hoje ele é uma pessoa extremamente conhecida no mercado e acredito que por ele ser conhecido, acaba que as pessoas associam o nome dele ao hospital. [Gestor 7]

De acordo com Berrone, Cruz, Gomez-Mejia (2012), a identidade do proprietário de uma empresa familiar está intrinsecamente ligada à organização. Os resultados da pesquisa mostram não só a identificação do proprietário, que é diretor-presidente da organização, bem como a identificação dos funcionários, clientes, fornecedores e prestadores de serviço com o diretor-presidente.

\section{Laços sociais obrigatórios}

Revista Gestão e Secretariado (GeSec), São Paulo, SP, v. 12, n. 3, set./dez., 2021, p. 37-63. 
Notou-se um forte engajamento e comprometimento dos funcionários, que têm como característica principal a lealdade à empresa e a seu proprietário. Eles ajudaram a construir a empresa nos bons e maus momentos conforme relato:

Falando do meu setor, que é o que vivencio, a grande maioria dos funcionários é comprometida com a empresa. É engraçada essa relação, você acaba se tornando parte da família. A forma de liderança dele faz com que você se sinta não só como mais um funcionário do hospital, mas como parte da família. E aí eu vejo que mesmo nas épocas em que o hospital passou por dificuldades financeiras, uma parcela grande da equipe ficou e continua no hospital até hoje. E aí pesa o lado pessoal que é característico da empresa familiar. [Gestor 5]

Além disso, há diversas ações sociais de engajamento e comprometimento da empresa com a comunidade. A empresa leva ambulâncias às praças do Rio de Janeiro, com palhaços e faz atendimento comunitário infantil. Um comprometimento pessoal do proprietário é fazer trabalho social com moradores de rua e entrega de mantimentos. No hospital tem a pet-terapia (terapia com o apoio de cachorros levados ao hospital), contador de histórias infantis, superheróis, apoio psicológico para as famílias das crianças internadas. O depoimento a seguir mostra este lado de afetividade e acolhimento do hospital:

A gente tem palhaçaria, tem contador de história, a gente tem a pet-terapia onde os cachorrinhos vêm pra fazer parte da terapia e do resultado para o paciente, para melhora do paciente. A gente empresta livros, tem a biblioteca, empresta brinquedo, tem a brinquedoteca, aí a gente tem a assistente social que ela vê o que aquela família precisa, às vezes a família tá aqui e não tem o que comer, tem plano de saúde, mas não tem o que comer. [Superintendente]

Em linha com os relatos dos gestores, o diretor-presidente contou histórias sobre os eventos que a empresa realiza, mesmo sem retorno financeiro, e a sua sensibilidade ao decidir em deixar internar de graça algum paciente que não tenha dinheiro para o tratamento. A seguir um dos episódios relatados:

O que eu faço sempre que me pedem para eu ver um paciente, eu fico sensibilizado com a história e deixo internar de graça no hospital. Exemplo, eu tenho um funcionário que eu gosto dele e a filha dele precisa de tratamento, eu interno de graça no hospital. A criança não tem plano de saúde, o cara trabalha comigo, me ajuda sempre. Então fica internada aqui, não procuro me meter se vai embora rápido ou se vai demorar. Como se eu tivesse fazendo uma filantropia. Sempre ajudo a todos os colaboradores por gratidão. Eu sou grato! [Diretor-presidente]

Para Vandekerkhof et al (2018), a riqueza socioemocional traduz a reunião de aspectos não financeiros da empresa familiar e necessidades afetivas da família. Além dos objetivos financeiros, este tipo de organização atribui maior importância à preservação da riqueza socioemocional, incluindo laços com a comunidade e funcionários. 


\title{
Apego emocional da família
}

Os relatos mostram que emoções, conflitos familiares e eventos afetaram o processo de tomada de decisão nos negócios. A maioria dos entrevistados destacaram dois eventos que abalaram o emocional do diretor-presidente da empresa: falecimento da esposa e crise financeira.

O falecimento da esposa fez com que o proprietário se concentrasse mais na gestão do hospital, deixando de atuar também como médico conforme a narrativa da herdeira:

\begin{abstract}
Antes da minha mãe falecer ele ainda ficava como médico no CTI, depois do que aconteceu ele é hoje muito mais gestor. Ele não entra mais no CTI, nada do que ele gosta de fazer como médico ele faz mais. Ele tem uma equipe grande de gestores com ele e ele virou muito mais empresário do que médico. [Herdeira]
\end{abstract}

Quanto à crise financeira, algumas narrativas ilustraram o envolvimento emocional do diretor-presidente com os funcionários:

A gente passou uma crise com uma operadora de planos de saúde e pela primeira vez o pagamento atrasou. E aquilo consumia ele de um jeito, a gente via. Até que ele passou e falou assim: "eu devo isso aos funcionários". E ele foi ao hospital e ele passou de andar em andar falando com cada funcionário. Eu vi uma técnica de enfermagem abraçada com ele e falando: "doutor... a gente vai passar dessa, eu tô orando muito!" [Gestor 9]

[...] ele pessoalmente foi até o chão de fábrica, dar a satisfação, pedir desculpas pelo atraso nos pagamentos, então aquilo foi algo que me emocionou muito como gestora... [Gestor 8]

De acordo com os funcionários, a empresa representa a missão de vida do diretorpresidente, sendo difícil imaginar que ele venha a vender a empresa:

[...] um dia eu cheguei e vi o doutor... abraçando uma criança que tinha acabado de morrer, ele entrou no CTI e ficou toda a madrugada... E ele vai fazer o que? Vai viver do que? [Gestor 3]

A narrativa do diretor-presidente reafirma o apego emocional à empresa conforme o relato a seguir:

[...] Hoje, eu passei essa crise toda, eu podia ter falado assim, não quero mais nada, mas eu já tô procurando um hospital para comprar. Eu não fiz isso por dinheiro (choro...), não tem dinheiro no mundo que pague... eu não fiz isso para vender, eu fiz isso porque é uma realização, entendeu? [Diretorpresidente]

Os resultados sobre a crise financeira enfrentada pela empresa familiar desta pesquisa corroboram o estudo de Minichilli, Brodi e Calabrò (2016), que confirmou a suposição central da perspectiva da riqueza socioemocional de que as vantagens das empresas familiares aparecem exatamente quando a propriedade está em jogo. As empresas familiares mostram 
resiliência nos momentos de crise e são mais capazes do que as outras de absorver choques exógenos.

\section{Renovação de laços familiares através da sucessão}

$\mathrm{Na}$ entrada do hospital tem-se um quadro com a foto dos seis fundadores, mostrando o orgulho e a história do legado da geração anterior, bem como o desejo da continuidade da empresa através da terceira geração.

Especialmente após o falecimento de sua esposa, a sucessão passou a ser uma preocupação do diretor-presidente, tornando-se parte dos planos para o futuro. Entretanto, a questão da sucessão no negócio ainda é uma incógnita, uma vez que os herdeiros nunca trabalharam na gestão da empresa. Nas suas palavras:

[...] Penso na empresa 30 horas. [...] Eles querem isso? Não sei!!! Nunca trabalharam na gestão. Não sei, é uma incógnita. [...] Então assim, sucessão é o desejo! A não ser que a economia mude, tudo muda. [Diretor-presidente]

De acordo com o herdeiro, o curso de gestão de empresas familiares mostra um movimento neste sentido da sucessão. Um dos gestores também comentou sobre a sucessão:

\footnotetext{
Acho que já está a caminho, já começou, logo que a gente entrou no curso de gestão de empresas familiares meu pai falou pra gente. $\mathrm{O}$ início do curso mostra esse movimento em relação à sucessão $\mathrm{e}$ todos os três querendo fazer junto o curso. Antes disso nunca teve nada... [...] Eu acho que eu vou ser um bom sócio! [Herdeiro]
}

Eu não sei se esse curso de gestão de empresas familiares que ele fez, ele e os filhos, se é um movimento com relação para a sucessão. Mas eu veria assim, com bastante orgulho, se os herdeiros tivessem esse vínculo de gestão e assumissem a sucessão. [Gestor 10]

Os estudos de Zellweger et al., (2011) e Frank et al. (2016) abordam as intenções das famílias para o controle transgeracional. Para Le Breton-Miller et al. (2004) a sucessão é um dos maiores desafios enfrentados pelas empresas familiares, sendo a preocupação mais importante de seus líderes. Em linha com a literatura, a sucessão na empresa pesquisada é uma preocupação e um dos maiores desafios do diretor-presidente atualmente.

Com base no exposto, constata-se a presença dos aspectos socioemocionais descritos pela teoria da riqueza socioemocional na gestão da empresa em escopo, conforme síntese apresentada na figura 4: 


\begin{tabular}{|c|c|}
\hline \multicolumn{2}{|r|}{ Riqueza socioemocional } \\
\hline Dimensões & Evidências encontradas \\
\hline $\begin{array}{l}\text { Controle e influência da } \\
\text { família }\end{array}$ & Influência do diretor-presidente na gestão através do controle sobre as decisões estratégicas. \\
\hline $\begin{array}{l}\text { Identificação de membros } \\
\text { da família com a empresa }\end{array}$ & $\begin{array}{l}\text { O diretor-presidente considera o hospital com um filho. Seus herdeiros consideram a } \\
\text { possibilidade de trabalharem na empresa, mostrando um entrelaçamento da família com os } \\
\text { negócios. }\end{array}$ \\
\hline Laços sociais obrigatórios & $\begin{array}{l}\text { Engajamento e comprometimento da empresa com a comunidade (Ex: ambulâncias nas praças, } \\
\text { internações gratuitas de filhos de funcionários, apoio psicológico e assistência social para as } \\
\text { famílias com poucos recursos que internam seus filhos no hospital). }\end{array}$ \\
\hline \begin{tabular}{|l|}
$\begin{array}{l}\text { Apego emocional dos } \\
\text { membros da família }\end{array}$ \\
\end{tabular} & $\begin{array}{l}\text { Envolvimento emocional do diretor-presidente com os funcionários e dificuldade de vender o } \\
\text { hospital mesmo em momentos de crise financeira. }\end{array}$ \\
\hline $\begin{array}{|lcr|}\begin{array}{l}\text { Renovação } \\
\text { familiares }\end{array} & \text { de } & \text { laços } \\
\text { sucessão } & & \text { da } \\
\end{array}$ & $\begin{array}{l}\text { Existência do desejo por parte do diretor-presidente para que os filhos assumam a gestão da } \\
\text { empresa. Os filhos seriam os futuros sócios da empresa, mantendo o poder nas mãos da família. }\end{array}$ \\
\hline
\end{tabular}

Figura 4. Aspectos socioemocionais presentes na gestão da empresa familiar

Fonte: Elaborado pelas autoras.

Os aspectos socioemocionais descritos na teoria da riqueza socioemocional influenciam a gestão e as decisões da empresa familiar desta pesquisa. A pesquisa mostra ainda a importância da preservação da riqueza socioemocional para a empresa familiar e aponta que questões como o controle familiar e reputação são importantes em linha com a base teórica adotada (Chen et al., 2014; Strike et al., 2015; Fang et al.,2016; Kabbach de Castro, Aguilera \& Crespi-Cladera, 2017 e Vandekerkhof et al., 2018).

Em seguida, a outra categoria temática identificada com base na análise dos dados e na revisão de literatura trata dos mecanismos de governança corporativa adotados pela empresa familiar.

\subsection{Mecanismos de Governança Corporativo}

O diretor-presidente participa das três esferas de poder (Gersick et al., 2017), ou seja, é proprietário de $100 \%$ das quotas de participação do capital social, pertence à família e é o principal gestor. De acordo com estudos anteriores de Mustakallio, Autio e Zahra (2002), não é incomum ver os proprietários de empresas familiares assumindo múltiplos papéis nas empresas como forma de exercer controle formal e informal.

A empresa não possui mecanismos formais de governança corporativa tais como um Conselho de Administração para auxiliar os gestores nos rumos dos resultados e nas estratégias da empresa. Esse tipo de órgão de governança é encontrado com frequência nas empresas de capital aberto, por obrigatoriedade legal (Lei 6.404/76), para garantir os direitos dos acionistas externos. Além disso, a empresa não possui por escrito regras ou regulamentos, código de conduta para os funcionários ou órgãos de fiscalização e controle como mecanismos previstos 
pelas práticas de governança corporativa reconhecidas no mercado (Aldrigh, 2003; Chrisman et al., 2018; Davis, 2019).

Em relação à governança familiar, não há um Conselho de Família que é o órgão responsável por manter assuntos de ordem familiar separados dos assuntos da organização (IBGC, 2015). No que tange à governança jurídico-sucessória não há uma estrutura de planejamento sucessório para os herdeiros da empresa. A governança jurídico-sucessória poderia contribuir para a implementação de regras de remuneração, regras para o ingresso da terceira geração na empresa (Ex: requisitos de formação para os herdeiros assumirem o negócio, experiência fora da empresa), bem como regras para a contratação de gestores externos (Prado et al., 2012).

Constatou-se, portanto, que não há uma estrutura formal de governança com órgãos ou procedimentos por escrito. Na visão do diretor-presidente:

[...] Essas estruturas de governança têm muito marketing. [Diretor-Presidente]

Neste contexto, existem outros mecanismos de controle na gestão da empresa pesquisada que não necessariamente os descritos na literatura. A centralização de poder e o controle das decisões nas mãos do diretor-presidente parecem desempenhar essa função:

Eu sei que tem uma pessoa para negociar com as operadoras de planos de saúde, ela é a negociadora, mas eu por trás, além dela mandar o e-mail, eu mando um e-mail para o presidente das operadoras, pra ela, pro outro cara, eu encho o saco, eu sou o sombra de todos, eu estou em todos os lugares, eu meto o dedo em tudo, eu quero saber de tudo, qualquer coisa eu chamo aqui na minha sala. [Diretor-Presidente]

O diretor-presidente atua na gestão e no planejamento estratégico da empresa, exercendo controle sobre as decisões estratégicas, em linha com a teoria da riqueza socioemocional:

\footnotetext{
Se você abrir meu computador, eu não tenho nada documentado aqui. Nada, eu não sigo nenhuma cartilha, eu sou intuitivo, eu não sou administrador, nunca me julguei administrador, eu sou médico. E sou assim, muita vontade de trabalhar e dar certo. A minha capacidade de trabalho supera minha clarividência na parte administrativa.

Quando a empresa era menor, ficava tudo na minha cabeça. Hoje a gente tem um programa bem atuante na empresa que é o de qualidade. E junto com a superintendente, a gente tem um planejamento estratégico definido para os próximos 3 anos. Então os gestores vão conduzindo as reuniões para esses planos. [Diretor-Presidente]
}

Todo o processo de controle da contratação e demissão de funcionários passa pelas mãos do diretor-presidente. $\mathrm{O}$ funcionário só é contratado com a assinatura do diretor-presidente e no caso de demissão de médicos só é desligado da empresa após uma entrevista para saber os motivos do pedido de demissão. Não existe um código de ética por escrito para direcionar a 
conduta dos funcionários, porém se o diretor-presidente souber que algum colaborador não está agindo com ética ou está tendo uma má conduta, ele é demitido imediatamente. O diretorpresidente fez o seguinte comentário:

Não existe código de conduta, porém se a gente vê que algum colaborador não está agindo com ética, com postura, com educação que eu saiba, porque às vezes não chega até a mim. Mas se eu tô sabendo, eu chamo para conversar imediatamente. Eu costumo dizer, erva daninha se espalha, assim que eu fico sabendo de uma má conduta, o desvio aqui é demitido imediatamente. [Diretor-presidente]

O mecanismo de controle para o comportamento ético do funcionário se dá pela cultura criada na empresa em relação ao comportamento esperado pelos funcionários. Assim, existe a ciência por parte dos funcionários de que o proprietário não admite desvios na empresa. De acordo com Anthony e Govindarajan (2006), a ética do trabalho, o estilo gerencial e a cultura são exemplos de processos informais numa organização. O estilo de gerenciamento impacta no controle gerencial, normalmente a atitude dos funcionários origina-se da atitude do executivochefe. A cultura é fortemente influenciada pela personalidade e pelas políticas do executivochefe. A ética do trabalho consiste no comportamento desejável na forma de lealdade dos funcionários à organização.

Ainda no que se refere a mecanismos de controle, o controle dos custos e do orçamento da empresa tem a interferência direta do diretor-presidente:

Todo o orçamento aqui passa pela minha mão pra eu assinar. Só compra uma peça do tomógrafo se eu assinar e se eu negociar. Eu negócio, às vezes, 100 reais aqui... A ambulância quebrou, eu ligo pro cara da oficina, esse preço eu não vou pagar. O ar-condicionado do carro do homecare quebrou... tudo eu sei. Aqui tudo eu quero saber... [Diretor-Presidente]

Diante do exposto, a análise demonstra que os mecanismos de governança corporativa da empresa familiar pesquisada são impactados pelos aspectos socioemocionais, o que faz com que se diferenciem dos mecanismos de governança usualmente descritos na literatura.

A empresa familiar participante desta pesquisa não possui uma governança corporativa com mecanismos formais para apoiar sua gestão, porém desenvolveu mecanismos informais que refletem os aspectos socioemocionais presentes na mesma. Assim, a empresa possui valores que praticamente a blindam contra mecanismos formais de governança.

A lógica familiar é impermeável à lógica da governança corporativa, o que freia a entrada de mecanismos formais de governança. O diretor-presidente gerencia diversidades, ele minimiza os conflitos e infunde os valores da família. Isso explica por que não existem mecanismos de governança formais em sua empresa e sim mecanismos de controle que atendem às necessidades da empresa preservando os valores familiares ressaltados por Bornholdt (2014), Gersick et al. (2017) e Chrisman et al. (2018). 
Para Chrisman et al. (2018) a governança geralmente é vista como a consequência de decisões formais tomadas pelos proprietários, gestores e conselho de administração de uma empresa para dirigir e controlar o comportamento de membros da organização. Porém isso ignora os processos informais dentro de uma organização que alcançam fins semelhantes de uma maneira que pode ser mais eficaz e/ou menos dispendiosa.

Sendo um hospital pediátrico, de acordo com Guerdert e Grosseman (2011), no atendimento à criança, os profissionais da saúde lidam com situações geradoras de problemas éticos, que requerem competência para a tomada de decisões. O diretor-presidente consegue lidar com tais situações, a partir da criação de mecanismos para implementação de uma cultura ética na empresa que serve de base para a tomada de decisões dentro da empresa. Para Binberg e Snodgrass (1988), a cultura afeta o controle.

Existe, portanto, um sistema de controle informal com mecanismos que direcionam o comportamento da empresa e de seus funcionários através da implementação de uma cultura ética. Para Tamayo, Mendes e Paz (2000), toda empresa cria sua própria cultura, seu próprio clima de trabalho, com crenças e valores próprios.

Com relação à sucessão, embora não haja um plano definido, como visto anteriormente, há um controle por parte do diretor-presidente em direcionar a sucessão na gestão para seus herdeiros. Por outro lado, a centralização do poder do diretor-presidente que permite minimizar conflitos, pode dificultar a sucessão. Como os mecanismos de controle estabelecidos pelo diretor-presidente são informais, os herdeiros precisarão ganhar legitimidade ao assumirem a direção do hospital.

Para Bertucci et al. (2009) o desenvolvimento de estruturas e mecanismos de governança corporativa influenciam a orientação e a mediação dos conflitos entre a família, a propriedade e a gestão em uma empresa familiar. Os mecanismos facilitam a condução do processo de sucessão para maior legitimidade e transparência (Arteaga \& Menéndez-Requejo, 2017). Neste contexto, não foram verificados mecanismos formais de governança para a condução do processo de sucessão. A sucessão é algo embrionário ainda e os herdeiros não fazem parte da gestão.

A figura 5 procura evidenciar como os mecanismos formais de governança são substituídos por mecanismos informais criados pelo diretor-presidente e que levam em consideração os aspectos socioemocionais. 


\begin{tabular}{|c|c|c|}
\hline Mecanismos inexistentes (formais) & Objetivo & Mecanismos existentes (informais) \\
\hline \multirow{2}{*}{ Conselho de Administração } & \multirow{2}{*}{\begin{tabular}{|l|} 
Auxiliar os gestores nos rumos dos \\
resultados e nas estratégias da empresa \\
\end{tabular}} & Controle sobre as estratégicas da empresa \\
\hline & & Controle das decisões e centralização de poder \\
\hline \multirow[t]{2}{*}{ Código de conduta para os funcionários } & \multirow[t]{2}{*}{ Promover princípios éticos na empresa } & $\begin{array}{l}\text { Controle para o comportamento ético do funcionário pela } \\
\text { cultura criada na empresa }\end{array}$ \\
\hline & & Controle para contratação e demissão de funcionários \\
\hline Órgãos de fiscalização e controle & $\begin{array}{l}\text { Fiscalizar e controlar a empresa para a } \\
\text { confiabilidade das informações }\end{array}$ & Controle dos custos e orçamento \\
\hline $\begin{array}{l}\text { Planejamento sucessório, regras de remuneração, } \\
\text { regras para o ingresso dos herdeiros na empresa }\end{array}$ & $\begin{array}{l}\text { Estabelecer regras básicas para o futuro } \\
\text { da empresa }\end{array}$ & $\begin{array}{l}\text { Controle do poder nas mãos da familia com início da } \\
\text { educação dos herdeiros para o papel de futuros sócios }\end{array}$ \\
\hline
\end{tabular}

Figura 5. Mecanismos de governança na empresa familiar Fonte: Elaborado pelas autoras

\section{Considerações Finais}

Este artigo procurou compreender como os aspectos socioemocionais presentes nas empresas familiares impactam os mecanismos de governança corporativa. A pesquisa foi realizada em uma empresa familiar brasileira da área de saúde, voltada para o setor de pediatria e presente no mercado há 59 anos.

Constatou-se a presença dos aspectos socioemocionais descritos pela Teoria da Riqueza Socioemocional na gestão da empresa em escopo, tais como: o controle e influência do proprietário familiar na gestão, o entrelaçamento entre família e negócio dando origem a uma identidade única da empresa familiar, os laços sociais obrigatórios neste tipo de empresa com os funcionários e a comunidade, o apego emocional da família aos negócios a necessidade de continuidade do negócio através da sucessão dos herdeiros da família.

Verificou-se ainda que a empresa não possui mecanismos formais de governança corporativa, bem como não possui por escrito regras ou regulamentos, código de conduta para os funcionários ou órgãos de fiscalização e controle como mecanismos previstos pelas práticas de governança corporativa. Ou seja, os resultados sugerem que, na prática, as empresas familiares sobrevivem sem mecanismos formais de governança corporativa, considerados por elas como mais voltados à prestação de contas a investidores externos do que destinados à solução de questões internas.

A empresa familiar foi construída a partir de seus valores e cultura que direcionam sua gestão. Existe um controle informal neste tipo peculiar de organização, onde os aspectos socioemocionais impactam seus mecanismos de governança corporativa.

Neste sentido, os mecanismos de governança corporativa descritos tradicionalmente na literatura parecem não atender às peculiaridades de algumas empresas familiares, que se tornam 
refratárias a eles, porque eles não levam em consideração os aspectos socioemocionais característicos destas empresas.

Por outro lado, a empresa analisada possui outros mecanismos de controle (apresentados no quadro 4) que foram desenvolvidos ao longo dos anos e que levam em consideração os valores da família e os aspectos socioemocionais presentes na organização.

A análise evidenciou que os mecanismos de governança corporativa sofreram impacto dos aspectos socioemocionais presentes na empresa familiar pesquisada. Assim, os aspectos identificados e analisados nesta pesquisa impactam nas decisões da empresa. Constatou-se que o controle e a influência direta do gestor afetam os negócios e que questões de amizade ou gratidão em relação aos funcionários impactam na tomada de decisão. Existe a interferência do dono da empresa no controle dos custos, orçamento e qualquer atividade da empresa em que achar que deva interferir. Além do desejo de sucessão nos negócios através dos herdeiros para a continuidade do legado e do controle da empresa pela família.

Os aspectos socioemocionais podem ser sutis e, portanto, de difícil captura e mitigação pelos mecanismos tradicionais de governança corporativa. Desta forma, as empresas familiares que muitas vezes têm interesse em implantar mecanismos formais para cuidar dos interesses de instituições e investidores externos (Teunissen, 2014; Briano-Turrenta \& Poletti-Hughesb, 2017), poderiam utilizar outros mecanismos que atendam às suas peculiaridades. Neste sentido, é necessário entender quais mecanismos de governança são úteis para diferentes tipos de empresas familiares (Nordqvist, Sharma \& Chirico, 2014), considerando que os aspectos socioemocionais presentes neste tipo de organização impactam tais mecanismos.

Para compreender como funciona a governança nessas empresas é preciso considerar que podem existir outros mecanismos que, não necessariamente, se encontram descritos na literatura. Os aspectos socioemocionais blindam as empresas familiares contra mecanismos de governança corporativa que se mostrem contrários aos valores da família. Dessa forma, os mecanismos formais de governança corporativa são substituídos por mecanismos informais de controle.

Este estudo contribuiu para a literatura sobre governança corporativa ao evidenciar que sua baixa efetividade junto às empresas familiares se deve ao fato de não atender às suas peculiaridades, ou seja, não levar em consideração os aspectos socioemocionais que permeiam a gestão dessas empresas, como os descritos na Teoria da Riqueza Socioemocional.

Neste sentido, a literatura sobre governança corporativa deveria incorporar e aceitar ao seu arcabouço conceitual outros mecanismos de governança que levassem em consideração aspectos socioemocionais, para que deixasse de ser inócua às empresas familiares, passando a 
contribuir efetivamente com a gestão e com a continuidade deste tipo de organização. A temática deste estudo é relevante para a área de gestão, pois envolve a discussão de aspectos socioemocionais que têm efeito sobre o comportamento de empresas familiares e influenciam suas decisões e mecanismos de governança.

Como sugestão para pesquisas futuras, recomenda-se que sejam realizados estudos com foco em governança e em aspectos socioemocionais em empresas familiares de diferentes portes, porque empresas de grande porte, por exemplo, já possuem mecanismos de governança constituídos conforme exigidos pelo mercado e preconizados na literatura. Também seria importante que as empresas já tivessem a sucessão concretizada, pois já poderiam ter instituído um Conselho de Família ou um Conselho de Acionistas para lidar com as questões de família e dos sócios. Assim, seria possível um maior aprofundamento nas análises para a avaliação dos resultados dos mecanismos de controle adotados pelas empresas familiares.

Por fim, como limitação desta pesquisa, considera-se que os relatos apresentados representam opiniões dos gestores sobre a percepção da realidade da empresa. Além disso, a escolha da análise qualitativa de conteúdo é realizada pela interpretação das autoras sobre a percepção dos entrevistados em relação ao assunto estudado.

\section{Referências}

Aldrighi, D. M. (2003). The Mechanisms of Corporate Governance in The United States: An Assessment. Revista Brasileira de Economia, 57, 469-513. http://dx.doi.org/10.1590/S0034-71402003000300001

Arteaga, R., \& Menéndez-Requejo, S. (2017). Family Constitution and Business Performance: Moderating Factors. Family Business Review, 1-19. $\underline{\text { https:// }}$ doi.org/10.1177/0894486517732438

Bauer, M. W., \& Gaskell, G. (2019). Pesquisa qualitativa com texto, imagem e som: Um manual prático. Rio de Janeiro: Vozes.

Bernhoeft, R. (2014). In: Revista Conexão SEBRAE - SP: De Pai para Filho: Sucessão planejada evita conflitos e assegura longevidade às empresas familiares. Disponível em:<http://www.sebrae.com.br/sites/PortalSebrae/ufs/pe/artigos/os-desafios-da- empresafamiliar-gestao-e-sucessao $>$. Acesso em: 30 jun. 2020.

Berrone, P., Cruz, C., \& Gomez-Mejia, L. R. (2012). Socioemotional Wealth in Family Firms: Theoretical Dimensions, Assessment Approaches, and Agenda for Future Research. Family Business Review, 25, 258-279. https://doi.org/10.1177/0894486511435355 
Bertucci, J. L. de O., Campos, E. A. da S.; Pimentel, T. D; \& Pereira, R. D. (2009). Mecanismos de Governança e Processos de Sucessão: um estudo sobre a influência dos elementos da governança corporativa na orientação do processo sucessório em uma empresa familiar. Revista Brasileira de Gestão de Negócios, 11(31), 152-167.

Birnberg, J., \& Snodgrass, C. (1988). Culture and control: a field study. Accounting Organizations and Society, v.13, p. 447-464. https://doi.org/10.1016/0361$\underline{3682(88) 90016-5}$

Bornholdt, W. (2014). Governança nas empresas de Controle Familiar. Gramado: Werner Bornholdt Consultores.

Bressan, A. A., Schiehll, E., Procianoy, J. L., \& Castro, L. R. K. (2019). Perspectivas da pesquisa em governança de empresas familiares no Brasil. Revista de Administração Contemporânea, 23(6), 696-702.

Briano-Turrenta, G. C., \& Poletti-Hughesb, J. (2017). Corporate governance compliance of family and non-family listed firms in emerging markets: Evidence from Latin America. Journal of Family Business Strategy. https://doi.org/10.1016/j.jfbs.2017.10.001

Capobianco, E. R. (2011). Empresas Familiares. São Paulo.

Carrieri, A P., Perdigão, D. A., \& Aguiar, A, R, C. (2014). A gestão ordinária dos pequenos negócios: outro olhar sobre a gestão em estudos organizacionais. Revista de Administração, São Paulo, 49(4), 698-713.

Chen, Q., Hou, W., Li, W., Wilson, C., \& Wu, Z. (2014). Family Control, Regulatory Environment, and the Growth of Entrepreneurial Firms: International Evidence. Corporate Governance: An International Review, 22, 132-144. https://doi.org/10.1111/corg.12060

Chrisman, J. J., Chua, J. H., Le Breton-Miller, I., Miller, D., \& Steier, L. P. (2018). Governance Mechanisms and Family Firms. Entrepreneurship Theory and Practice, 42(2) 171-186. https://doi.org/10.1177/1042258717748650

Chua, J. H., Chrisman, J. J., Sharma, P. (1999) Defining the family business by behavior. Entrepreneurship Theory and Practice, 23, 19-39. https://doi.org/10.1177/104225879902300402

Ciftci, I., Tologlu, E., Wood, G., Demirbag, M., \& Zaim, S. (2019). Corporate governance compliance of family and non-family listed firms in emerging markets: Evidence from Latin America. Journal of Family Business Strategy. https://doi.org/10.1016/j.jfbs.2017.10.001

Davis, J. A. (2019). Leading the Family Business System: It takes a Village. Part Two: Structuring Leadesrhip Roles. Cambridge Institute for Family Enterprise.

Fang, H, C., Randolph, R. V. D. G., Memili, E., \& Chrisman, J. J. (2016). Does Size Matter? The Moderating Effects of Firm Size on the Employment of Nonfamily Managers in 
Privately Held Family SMEs. Entrepreneurship Theory and Practice. https://doi.org/10.1111/etap.12156

Frank, H., Kessler, A., Rusch, T., Suess-Reyes, J., \& Weismeier-Sammer, D. (2016). Capturing the familiness of Family businesses: Development of the Family influence familiness scale (FIFS). Entrepreneurship Theory and Practice, 41, 1-34. https://doi.org/10.1111/etap.12229

Fonseca, W. C., Jr. (2005). Métodos e técnicas de pesquisa em comunicação. In DUARTE, J.; BARROS, A..; (Org.). São Paulo: Atlas.

Gerhardt, T. E., \& Silveira, D. T. (2009). Métodos de pesquisa. Porto Alegre: Editora da UFRGS.

Gersick, K. E., Davis, J. A., Hamptom, M., \& McC, L. I. (2017). De Geração para Geração: ciclos de vida das empresas familiares. Rio de Janeiro: Alta Books.

Golden, J., \& Kohlbeck, M. J. (2016). The influence of family firm dynamics on voluntary disclosures. Advances in Accounting, incorporating Advances in International Accounting. https://doi.org/10.1016/j.adiac.2016.11.003

Guerdert, J. M; \& Grosseman, S. (2011). Abordagem dos Problemas Éticos em Pediatria: Sugestões Advindas da Prática. Revista Brasileira de Educação Médica, 35(3), 359-368. https://doi.org/10.1590/S0100-55022011000300009

Instituto Brasileiro de Governança Corporativa. (2015). Código das melhores práticas de governança corporativa. Disponível em: <http://www.ibgc.org.br>. Acesso em: 09 ago. 2020 .

Instituto Brasileiro de Governança Corporativa. (2016). Governança da Família Empresária: Conceitos Básicos, Desafios e Recomendações (Série Cadernos de Governança Corporativa, 15. Disponível em: <http://www.ibgc.org.br>. Acesso em: 09 ago. 2020.

Kabbach C. L. R., Aguilera, R. V., \& Crespí-Cladera, R. (2017). Family Firms and Compliance: Reconciling the Conflicting Predictions Within the Socioemotional Wealth Perspective. Family Business Review. https://doi.org/10.1177/0894486516685239

Lee, K., Makri; M. D., \& Scandura, T. A. (2019) The Effect of Psychological Ownership on Corporate Entrepreneurship: Comparisons Between Family and Nonfamily Top Management Team Members. Family Business Review, 1-21. https://doi.org/10.1177/0894486518785847

Liu, Y., Valenti, A., \& Chen, Y. (2016). Corporate governance and information transparency in Taiwan's public firms: The moderating effect of family ownership. Journal of Management \& Organization, 662-679. https://doi.org/10.1017/jmo.2015.56 
Minichilli, A., Brodi, M., Calabrò, A. (2016). Weathering the Storm: Family Ownership, Governance, and Performance Through the Financial and Economic Crisis. Corporate Governance: An International Review. https://doi.org/10.1111/corg.12125

Mustakallio, M., Autio, E., \& Zahra, S. A. (2002). Relational and contractual governance in family firms: Effects on strategic decision making. Family Business Review. https://doi.org/10.1111/j.1741-6248.2002.00205.x

Nordqvist, M., Pramodita, S., \& Chirico, F. (2014). Family Firm Heterogeneity and Governance: A Configuration Approach. Journal of Small Business Management, 52, $192-$ 209. https://doi.org/10.1111/jsbm.12096

Perry, J. T., Ring, J. K., \& Broberg, J. C. (2015). Which type of advisors do family businesses trust most? An exploratory application of socioemotional selectivity theory. Family Business Review, 28(3), 211-226. https://doi.org/10.1177/0894486514538652

Prado, R. N. (2012). Direito, gestão e prática: empresas familiares: governança corporativa, governança familiar e governança jurídica. São Paulo: Saraiva.

Steinberg, H., \& Blumenthal, J. (2011). A Família Empresária: Organizando as relações de afeto, poder e dinheiro por meio da governança corporativa. São Paulo: Gente.

Steir, L. P., Chrisman, J. J., \& Chua, J, H. (2015). Governance Challenges in Family Businesses and Business Families. Entrepreneurship Theory and Practice. https://doi.org/10.1111/etap.12180

Strike, V. M., Berrone, P., Sapp, S, G., \& Congiu, L. (2015). A Socioemotional Wealth Approach to CEO Career Horizons in Family Firms. Journal of Management Studies, 52. https://doi.org/10.1111/joms.12123

Tamayo, A., Mendes, A. M.; \& Paz, M. G. T. (2000). Inventário de valores organizacionais. Estudos de Psicologia, 5(2), 289-315.

Teunissen, L. J. T. (2014). Corporate Governance Mechanisms of Family Firms in the Netherlands. Master Thesis International Business Law. Tilburg Law School.

Vandekerkhof, L. R., Steijvers, T., Hendriks, W., \& Voordeckers, W. (2018). Socio-Emotional Wealth Separation and Decision-Making Quality in Family Firm TMTs: The Moderating Role of Psychological Safety. Journal of Management Studies, 55. https://doi.org/10.1111/joms.12277

Yin, R. K. (2015). Estudo de caso: planejamento e métodos. 5.ed. Porto Alegre: Bookman.

Submetido em: 26.12.2020

Aceito em: $\quad 10.04 .2021$ 